The results of a typical experiment are as follow : Compound

Total radioactivity per Warburg flask (counts per minute)

Citrate

$a$-Ketoglutarate dinitrophenylhydrazone

Carbon dioxide from

Succinate from

,

11,300
2,550
2,470
$<70$

It is apparent that the $\alpha$-ketoglutaric acid was labelled solely in the carboxyl group adjacent to the carbonyl group. Hence, as revealed by enzymatic means, the citric acid must have been labelled exclusively in one of the two 'identical' carboxyl groups. These data thus fully substantiate the concept set forth by Ogston ${ }^{1}$ relative to the experiments that were earlier used to eliminate citric acid from the Krebs 'citric acid cycle'.

It is interesting to note that the recent data by Stern and Ochoail on the biosynthesis of citric acid are now seen to be compatible with the data of the earlier tracer experiments ${ }^{2,3}$, although incompatible with the conclusions drawn from them.

It is a pleasure to acknowledge our gratitude for the assistance of Profs. R. H. Burris and G. A. LePage, Dr. R. E. Stutz, Mr. L. S. Watson and Mrs. G. G. Lyle in carrying out these experiments.

This work was supported by a grant from the American Cancer Society on the recommendation of the National Research Council Committee on Growth, and by a grant from the U.S. Public Health Service.

VAN R. POTTER

Charles Heidelberger

McArdle Memorial Laboratory for

Cancer Research,

Medical School,

University of Wisconsin. June 7.

' Ogston, A. G., Nature, 162, 4129 (1948)

${ }^{2}$ Evans, E. A., jun., and Slotin, I., J. Biol. Chem., 141, 439 (1941).

${ }^{3}$ Wood, H. G., Werkman, C. H., Hemingway, A., and Nier, A. O., J. Biol. Chem., 142, 31 (1942).

4 Wood, H. G., Physiol. Rev., 26, 198 (1946).

${ }^{5}$ Potter, V. R., Pardee, A. B., and Lyle, G. G., J. Biol. Chem., 176 1075 (1948).

6 Watson, L. S., Heidelberger, C., and Potter, V. R. (unpublished)

" Isherwood, F. A., Biochem. J., 40, 688 (1946).

\& Potter, V. R., and Lyle, G, G. (unpublished).

- LePage, G. A. (unpublished).

${ }^{10} \mathrm{Krebs}$, H. A., Biochem. J., 32, 108 (1938).

"Stern, J. R., and Ochoa, S., J. Biol. Chem., 179, 491 (1949).

\section{Synthesis of Pyrazine Cyclic Hydroxamic Acids Related to Aspergillic Acid}

AsPERGILIIC acid is a pyrazine cyclic hydroxamic acid of structure (I). Although a general method has been developed for the synthesis of pyridine and quinoline cyclic hydroxamic acids ${ }^{1}$, attempts to apply this method in order to effect a synthesis of a pyrazine cyclic hydroxamic acid have been unsuccessful, per. oxidation of a 2-substituted pyrazine giving the 4-oxide and not the required 1-oxide ${ }^{2}$. We now describe two syntheses of pyrazine cyclic hydroxamic acids starting from $\alpha$-aminohydroxamic acids (III), which are readily obtained by the action of hydroxylamine on $\alpha$-amino-esters.

Condensation of $\alpha$-aminohydroxamic acids (II) with $1: 2$-dicarbonyl compounds (III) gives pyrazine cyclic hydroxamic acids (IV). The properties of the acids (IV) closely resemble those of aspergillic acid. In particular, they give a strong ferric reaction and, on reduction with hydrazine, each is converted into a hydroxypyrazine identical with the corresponding hydroxypyrazine obtained by the condensation of an $\alpha$-amino-acid amide with a 1:2-dicarbonyl compound $^{3}$. Using a $1: 2$-keto-aldehyde such as methylglyoxal (III, $R^{\prime}=\mathrm{Me}, R^{\prime \prime}=\mathrm{H}$ ) or phenylglyoxal (III, $R^{\prime}=\mathrm{Ph}, R^{\prime \prime}=\mathrm{H}$ ) as the dicarbonyl component, the reaction gives a $3: 5$-disubstituted cyclic hydroxamic acid (IV, $R^{\prime}=$ Me or $\mathrm{Ph}, R^{\prime \prime}=\mathrm{H}$ ) exclusively and not the isomeric 3:6-disubstituted acid (IV, $R^{\prime}=\mathrm{H}, R^{\prime \prime}=\mathrm{Me}$ or $\mathrm{Ph}$ ). Considerable changes in the reaction conditions did not vary this experience; consequently the method will not serve for a synthesis of aspergillic acid (I).

A suitable method for the synthesis of a $3: 6$ disubstituted pyrazine cyclic hydroxamic acid has been developed. Glycine hydroxamic acid (II, $R=H$ ) reacts with 2 -bromocinnamaldehyde to give

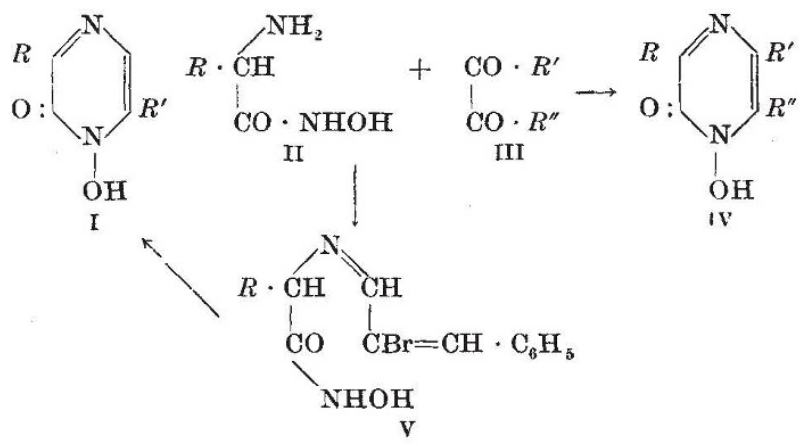

the Schiff base (V, $R=\mathrm{H}$ ) which, on treatment with sodium alkoxide, gives the cyclic hydroxamic acid (I, $R=\mathrm{H}, R^{\prime}=\mathrm{CH}_{2} \mathrm{Ph}$ ). Similarly, treatment of 2 -bromocinnamaldehyde with $\alpha$-amino- $n$-butyrohydroxamic acid (II, $R=\mathrm{Et}$ ) gives the Schiff base (V, $R=\mathrm{Et}$ ), which is cyclized by treatment with potassium $t$-butoxide to give 1-hydroxy-2-keto-3ethyl-6-benzyl-1 : 2-dihydropyrazine (I, $R=\mathrm{Et}, R^{\prime}=$ $\mathrm{CH}_{2} \mathrm{Ph}$ ). This method, or a simple variant, offers a route to the synthesis of aspergillic acid. The method is attractive in that it allows the introduction of difierent substituents at the 3- and 6-positions, a feature which will be of value in deciding between the alternative formulæ (I, $R=$ sec. $-\mathrm{C}_{4} \mathrm{H}_{9}, R^{\prime}=$ iso $\left.-\mathrm{C}_{4} \mathrm{H}_{9}\right)$ and $\left(\mathrm{I}, R=i s o \cdot \mathrm{C}_{4} \mathrm{H}_{9}, R^{\prime}=\right.$ sec. $\left.-\mathrm{C}_{4} \mathrm{H}_{9}\right)$ for aspergillic acid.

George Dunn D. W. C. Ramsay

J. A. Elvidge F. S. Spring

G. T. Newbold WILFRED SWEENy

Royal Technical College,

Glasgow. June 16.

${ }^{1}$ Newbold and Spring, J. Chem. Soe., 1864 (1948).

2 Baxter, Newbold and Spring, $J$. Chem. Soc., 1859 (1948).

${ }^{3}$ Jones, J. Amer. Chem. Soc., 71, 78 (1949).

\section{Fractionation of Thyroid lodine by means of Filter-Paper Partition Chromatography}

By means of filter-paper partition chromatography, Fink, Dent and Fink ${ }^{1}$ located several different radioiodine fractions in hydrolysates prepared from thyroids of rats that had been injected 24-28 hours earlier with iodine-131. Surprisingly, little or none of the radioactivity was found as thyroxine. Since this is not in accord with previous results from this laboratory ${ }^{2}$, we examined the method of filter-paper chromatography as applied to thyroid iodine. 